\title{
ANALYSIS OF CHROMOSOME V AND THE ILV1 GENE FROM SACCHAROMYCES CARLSBERGENSIS
}

\author{
by \\ TORSTEN NILSSON-TILLGREN ${ }^{1}$, CLAES GJERMANSEN, STEEN HOLMBERG, \\ JENS G. LITSKE PETERSEN \\ and
}

MORTEN C. KIELLAND-BRANDT

Department of Physiology, Carlsberg Laboratory, Gamle Carlsberg Vej 10, DK-2500 Copenhagen Valby

1) Institute of Genetics, University of Copenhagen, Øster Farimagsgade 2A, DK-1353 Copenhagen K

Keywords: Homoeologous recombination, restriction fragment length polymorphism, $C A N I$, URA3, CYC7, ILV1 genes, cloning, threonine deaminase, yeast, Saccharomyces cerevisiae

Chromosome V of the Saccharomyces carlsbergensis lager yeast strain 244, a yeast not amenable to tetrad analysis, was analysed genetically in S. cerevisiae genetic standard strains. This was achieved by crossing meiotic progeny of the lager yeast with S. cerevisiae strains carrying karl as well as the chromosome V markers canl, ura3, his 1 , ilv 1 , and rad3. From the transitory heterokaryons formed we selected strains retaining the characteristics of the recipient strain but having become prototrophic for uracil, histidine, and isoleucine. The resulting strains were disomic for chromosome $\mathrm{V}$, having acquired a chromosome $\mathrm{V}$ from $\mathrm{S}$. carlsbergensis in addition to the normal S. cerevisiae chromosome complement (chromosome addition strains). They were of two classes: In one class the transferred chromosome hardly recombines with the $\mathrm{S}$. cerevisiae chromosome $\mathrm{V}$ in the region $C A N I-R A D 3$, which covers almost the entire known map. In the other class, the transferred chromosome recombined at normal levels. We conclude that $\mathrm{S}$. carlsbergensis harbors two structurally different chromosomes $\mathrm{V}$; one being homologous and one homoeologous to the $\mathrm{S}$. cerevisiae chromosome. By use of the CANI locus, strains were selected which by mitotic chromosome loss had their normal chromosome $\mathrm{V}$ substituted by either the homologous or the homoeologous S. carlsbergensis chromosome, showing that these chromosomes are fully functional in S. cerevisiae. Tetrad analysis of the chromosome substitution strains confirmed the very different genetic behavior of the two S. carlsbergensis chromosomes $\mathrm{V}$. In spite of the almost complete absence of recombination between the homoeologous chromosome and the $\mathrm{S}$. cerevisiae chromosome, disjunction at meiosis appears normal, as indicated by high spore viability.

Genomic Southern hybridizations with the probes CAN1, URA3, CYC7, and ILVI could not detect any nucleotide sequence differences between these loci on the recombining $\mathrm{S}$. carlsbergensis chromosome and the $\mathrm{S}$. cerevisiae alleles. Under standard stringency $\left(68^{\circ} \mathrm{C}, 0.1 \times \mathrm{SSC}\right)$, hybridization of the probes to DNA from the strain with the homoeologous chromosome was only observed in the case of $I L V I$, where weak hybridization was found, indicating a considerable difference in nucleotide sequence.

To further study the extent of nucleotide sequence inhomology, the two different $I L V I$ genes of S. carlsbergensis

Abbreviations: $\mathrm{cM}=$ centiMorgan; $\mathrm{kb}=$ kilobase pairs; $\mathrm{SSC}=0.15 \mathrm{M}-\mathrm{NaCl}, 0.015 \mathrm{M}$-sodium citrate, $\mathrm{pH} 7.0$. 
were cloned in $\lambda$ vectors. Mapping of 16 restriction enzyme sites showed identity between the allele located on the recombining chromosome and the $I L V I$ gene of $\mathrm{S}$. cerevisiae. The nucleotide sequence of the $I L V I$ gene of the non-recombining chromosome was by restriction site mapping found to be very different from that of the $S$. cerevisiae allele.

\section{INTRODUCTION}

Saccharomyces carlsbergensis strain 244 is used for lager beer production. Like many other industrial yeasts it does not express a mating type and sporulates poorly with irregular asci containing mostly unviable ascospores. The germinating spores produce strains with either $a, \alpha$, or non-mating phenotypes. Crosses of such meiotic segregants with mating type to haploid genetic standard strains give hybrids which produce more regular asci, but still a very low proportion of the ascospores is viable (7). Because of this problem we use the single chromosome transfer technique (21) for the genetic characterization of $\mathrm{S}$. carlsbergensis instead of conventional tetrad analysis of hybrids between the brewing strain and laboratory tester strains. This technique makes use of the karl mutation (4) which strongly reduces the frequency of karyogamy after zygote formation. It has been found $(5,20)$ that one or a few chromosomes may be transferred from one nucleus to another in heterokaryons formed in $K A R l \times k a r l$ crosses. Also in the case of crosses between S. carlsbergensis and a karl carrying S. cerevisiae strain, heterokaryons are formed and single chromosomes may be transferred. Thus, it is possible to isolate a $\mathrm{S}$. carlsbergensis chromosome in a genetically well marked S. cerevisiae strain, where the chromosome subsequently can be analysed by tetrad analysis (21). With this method we have demonstrated that (i) S. carlsbergensis contains two structurally rather different chromosomes III $(9,21)$, (ii) at least one of the chromosomes is functionally homologous to the S. cerevisiae chromosome III, and (iii) recombination with S. cerevisiae chromosome III occurs only in a limited region. By molecular hybridization using probes of cloned DNA from S. cerevisiae we showed that the non-recombining part of the chromosome contains genes ( $H M L, H I S 4, L E U 2$, and $M A T)$ which differ in base sequence from the equivalent $\mathrm{S}$. cerevisiae genes (9).
In the present communication we present genetic as well as molecular evidence for the presence in $\mathrm{S}$. carlsbergensis of two different chromosomes V. Both types of chromosome are functional in S. cerevisiae, i.e. all essential genes normally harbored on chromosome $\mathrm{V}$ are also present on the carlsbergensis chromosomes. One of the chromosomes is homologous to the $\mathrm{S}$. cerevisiae chromosome as normal recombination frequencies are obtained. We call the other chromosome homoeologous to the S. cerevisiae chromosome as virtually no recombination with the latter is found. Parts of these results have been presented previously $(11,13$, $22,29)$.

\section{MATERIALS AND METHODS}

\subsection{Strains, media, and genetic methods}

All genetic methods employed in this study have been described in earlier publications $(9$, 20, 21). Canavanine medium is a synthetic complete medium lacking arginine and containing $60 \mathrm{mg} / \mathrm{l}$ canavanine.

A list of yeast strains used in this study is found in Table I.

\subsection{Molecular hybridization}

Molecular hybridization (Southern blot analysis (28)) was carried out as described by HoLMBERG (9).

\subsection{Molecular cloning of $I L V I$ genes from $\mathrm{S}$. carlsbergensis}

The $I L V 1$ alleles of $\mathrm{S}$. carlsbergensis were cloned in bacteriophage $\lambda$ by standard methods (16). Phage vectors NM781 (19) and L47 (15), respectively, were used in two different experiments. Recombinant phages with ILVI sequences were identified by the plaque hybridization method of BENTON and DAVIS (1). The probe was plasmid pC519 containing a $6.1 \mathrm{~kb}$ HindIII - SalI DNA fragment with the entire 
Table I. Yeast strains used in chromosome transfer and genetic crosses.

\begin{tabular}{|c|c|c|c|}
\hline Strain & Genotype & \multicolumn{2}{|c|}{ Source } \\
\hline \multicolumn{4}{|c|}{ Saccharomyces carlsbergensis strains } \\
\hline 244 & Saccharomyces carlsbergensis, brewing strain & (7) & \\
\hline C80-CG 110 & Spore derived clone from strain $244, M A T \alpha$ & (7) & \\
\hline $\mathrm{C} 80-\mathrm{CG} 7$ & Spore derived clone from strain $244, M A T$ a & (7) & \\
\hline \multicolumn{4}{|l|}{ karl recipients } \\
\hline C80-II- 17 & $\begin{array}{l}\text { MATa canl ura3 hisl ilv1 rad3 ade } 2 \text { cyh2 } \\
\text { karl-1 }\end{array}$ & \multicolumn{2}{|c|}{ This study } \\
\hline 090780-BIV-37 & $\begin{array}{l}\text { MATa canl ura } 3 \text { his } 1 \text { ilv1 rad3 ade } 2 \text { cyh2 } \\
\text { leu2 karl-1 }\end{array}$ & “ & “ \\
\hline 080182-B51 & $\begin{array}{l}\text { MAT a ura3 hisl ilv1 rad } 3 \text { ade2 cyh2 } \\
\text { karl-1 }\end{array}$ & “ & “ \\
\hline \multicolumn{4}{|l|}{ Tester strains } \\
\hline $240380 \mathrm{~B}-55$ & MATa ura3 his1 ilv1 rad3 trpl leu2 & “ & “ \\
\hline $040380 \mathrm{I}-56$ & MATa ura 3 his I ilv1 rad3 leu 2 & “ & “ \\
\hline 230480 CI-14 & MATa ura 3 hisI canI trpl cyh2 & “ & “ \\
\hline $040380 \mathrm{I}-47$ & MAT $\alpha$ ura3 ilv1 rad3 trp1 leu2 & “ & “ \\
\hline \multicolumn{4}{|c|}{ Chromosome $\mathrm{V}$ addition strains } \\
\hline IXX18 & $\begin{array}{l}\text { MAT } \mathbf{a}^{+} / \mathrm{canl}+/ \mathrm{ura}^{+}+/ \mathrm{his} 1^{+} / \mathrm{ilvl}+/ \mathrm{rad} 3 \\
\text { ade } 2 \text { cyh2 karl-1 }\end{array}$ & “ & “ \\
\hline IXX11 & $\begin{array}{l}\text { MAT } \mathbf{a}^{+} / \text {canl }+/ \text { ura } 3^{+} / \text {his } 1+/ i l v 1+/ \text { rad } 3 \\
\text { ade } 2 \text { cyh2 karl-1 }\end{array}$ & “ & “ \\
\hline IXX3 & $\begin{array}{l}\text { MAT a canl/canl }+/ \text { ura } 3+/ h i s 1+/ i l v 1+/ r a d 3 \\
\text { ade } 2 \text { cyh } 2 \text { karl-1 }\end{array}$ & “ & “ \\
\hline C $80-1607$ & $\begin{array}{l}\text { MAT a canl/canl }+/ \text { ura3 }+/ \text { hisl }+/ i l v 1+/ \text { rad } 3 \\
\text { ade } 2 \text { cyh } 2 \text { karl-1 }\end{array}$ & “ & $“$ \\
\hline \multicolumn{4}{|c|}{ Chromosome $V$ substitution strains } \\
\hline C80-1609 & $\begin{array}{l}\text { MATa CANI URA3 HISI ILVI RAD } 3 \text { ade2 cyh2 } \\
\text { karl-1 }\end{array}$ & “ & “ \\
\hline 250382-4A-I & $\begin{array}{l}\text { MATa canl URA3 HIS1 ILVI RAD3 ade } 2 \text { cyh2 } \\
\text { karl-1 }\end{array}$ & “ & “ \\
\hline \multicolumn{4}{|c|}{ Transformable strain } \\
\hline C81-1431 & MAT a ilv1-23 trpl ura4 arg4 ade2 & (24) & \\
\hline
\end{tabular}

ILVl gene from S. cerevisiae (24) in pBR322 (see Figure 4). Plasmid pCI-1 is pC508 (pBR325$T R P l-A R S 1$ ) (24), with a $12 \mathrm{~kb}$ BamHI fragment containing a $\mathrm{S}$. carlsbergensis $I L V I$ allele recovered from the recombinant phage $\lambda$ L47R6. pC551 is pUR222 with a S. cerevisiae 1.077 $\mathrm{kb}$ PstI fragment (14) containing $54 \%$ of the ILVI coding region. pC552 is pUR222 with a S. cerevisiae $1.7 \mathrm{~kb}$ PstI fragment (24) 5 ' to the ILVI coding region.

\subsection{Transformation}

For transformation of yeast cells the Li-acetate method of ITO et al. (12) was used. Escherichia coli strain HB101 was transformed according to MANIATIS et al. (16).

\subsection{Electrophoretic karyotyping}

The method described by CARLE and OLSON (3) was used for the electrophoretic separation of chromosomal DNA. 


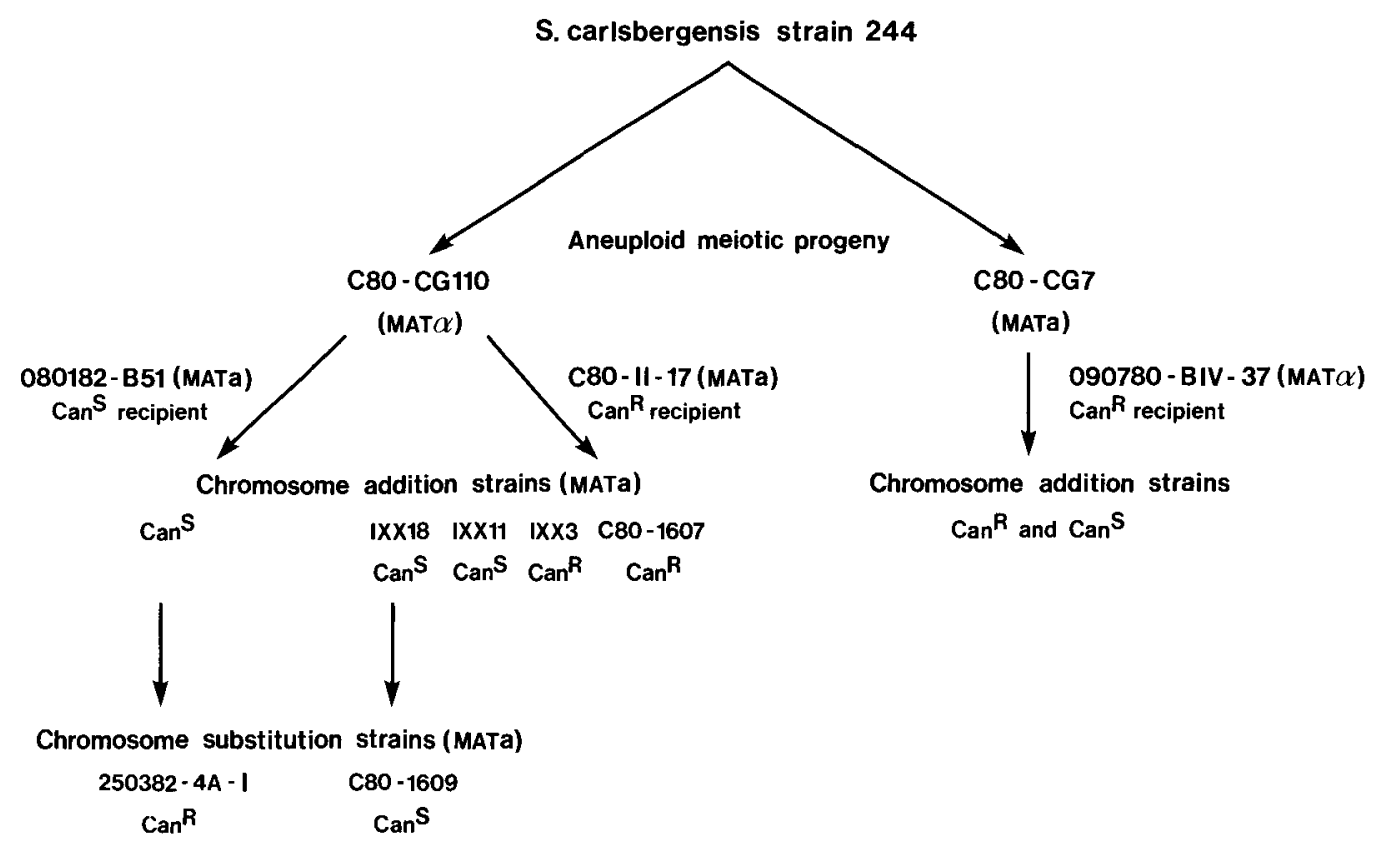

Figure 1. The construction of chromosome $\mathrm{V}$ addition and substitution strains from meiotic progeny of the $\mathrm{S}$. carlsbergensis lager brewing strain 244 .

\section{RESULTS}

\subsection{Transfer of chromosome $V$}

Strain C80-CG110 is a meiotic segregant of the S. carlsbergensis brewing strain 244 (see Figure 1). It grows well on both synthetic and complex media and expresses mating type $\alpha$ efficiently. This strain was chosen as donor for the transfer of chromosome V from S. carlsbergensis to $\mathrm{S}$. cerevisiae. The recipient strain, C80-II-17, is a haploid laboratory strain carrying the karl mutation, several chromosome $\mathrm{V}$ markers (can1, ura3, ilv1, hisl, and rad3), a recessive gene for resistance to cycloheximide (cyh2) located on chromosome VII and the chromosome XV marker ade 2 which gives a red colony colour. Approximately equal numbers of log phase cells from the two strains were mixed and plated densely on a YPD plate which was left for 6 hours at $30^{\circ} \mathrm{C}$ followed by 20 hours at $20^{\circ} \mathrm{C}$. The cells were then washed off the plate, washed twice in water, diluted and plated on YPD as well as on media selective for chromosome V markers: cycloheximide containing synthetic complete medium lacking histidine, uracil, and isoleucine, singly or in combinations. Products of the transfer of chromosome $\mathrm{V}$ should be histidine, uracil and/or isoleucine prototrophic, while retaining cycloheximide resistance and red colony colour. Neither donor nor recipient can grow on these media. The same is true for hybrid progeny resulting from complete karyogamy, since $c y h 2$ is recessive. Red as well as white colonies appeared after incubation for several days at $30^{\circ} \mathrm{C}$. On the selective plates the red colonies were about 10 times more frequent than the white ones. The latter category was not further analysed; most of them are supposed to be diploids that have become homozygous for cyh 2 by mitotic recombination. True hybrids between the donor and the recipient strains form white colonies on YPD that are bigger than the white colonies of the donor strain. This makes it possible to calculate the frequency of red $\mathrm{His}^{+}, \mathrm{Ura}^{+}, \mathrm{Ile}^{+}$, $\mathrm{Cyh}^{\mathrm{R}}$ colonies relative to true hybrids. This frequency was found to be $2 \times 10^{-3}$. In a control experiment involving only $\mathrm{S}$. cerevisiae strains this frequency was in the same order, $1.2 \times 10^{-3}$. 
Four hundred and fifty-eight red colonies were isolated from the cycloheximide containing plates and tested for auxotrophic requirements, canavanine resistance and mating type. They were all $\mathrm{His}^{+}, \mathrm{Ile}^{+}$, and $\mathrm{Ura}^{+}$, no matter which of the media they were selected on. Ninety percent of them had retained the mating type of the recipient strain and almost all of the remaining $10 \%$ were non-maters and non-sporulators. Unexpectedly, a large fraction (38\%) were canavanine resistant, a result analyzed in 3.2 . The red cycloheximide resistant colonies have received genetic information from $S$. carlsbergensis making them prototrophic for histidine, uracil, and isoleucine, while they for the ade 2 and $c y h 2$ genes, and most often also for the MAT gene, have retained the phenotype of the recipient strain. Since the mutations complemented in the recipient strain are all located on the $S$. cerevisiae chromosome $\mathrm{V}$, the prototrophic colonies were supposed to be chromosome addition strains, i.e. they are carrying a $S$. cerevisiae complement with an additional chromosome $\mathrm{V}$ from $S$. carlsbergensis. This notion was supported by the fact that reversion to auxotrophy for one of the three nutrients was always associated with a reversion for the two others. Such reversion by mitotic chromosome loss was observed with a frequency of approximately $1 \%$ after growth in non-selective medium for 8-10 generations.

Very similar results were obtained when strain C80-GC7, another meiotic offspring of strain 244, was used as a donor (Figure 1). In this case, strain 090780-BIV-37 was the recipient and again both $\mathrm{Can}^{\mathrm{S}}$ and $\mathrm{Can}^{\mathrm{R}}$ colonies were found among the histidine, isoleucine, and uracil prototrophs.

\subsection{Tetrad analysis of presumptive chromosome addition strains}

To further investigate the nature of the prototrophic colonies described above, we crossed

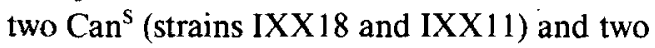
$\mathrm{Can}^{\mathrm{R}}$ isolates (strains IXX3 and C80-1607) (see Figure 1) to chromosome $\mathrm{V}$ tester strains. The resulting diploids, presumed to be trisomic for chromosome $\mathrm{V}$, were sporulated and subjected to tetrad analysis. The two $\mathrm{Can}^{\mathrm{s}}$ clones were both crossed to strain 240380B-55. The results are shown in Table II. Except for canl, which will be dealt with in more detail below, all markers investigated segregated $2: 2$. The absence of $1: 3$ segregation for any of the chromosome $\mathrm{V}$ genes indicates that the $\mathrm{S}$. carlsbergensis chromosome did not participate in any crossover (cf. ref. 6). That this is indeed the case is shown by the distribution of different tetrad types. Note the almost complete absence of TT and NPD types of asci for the markers HISI, $I L V 1$, and $U R A 3$. The genes appear to be tightly linked and, except for one case, no recombination takes place between the URA3, HISI, and $\mathrm{ILVl}$ genes introduced from $\mathrm{S}$. carlsbergensis and the equivalent $S$. cerevisiae genes on chromosome $\mathrm{V}$ of the tester or recipient strain.

In the crosses in Table II, the canl gene was difficult to score because of the presence of intermediate phenotypes. Nine tetrads of the upper cross were more closely investigated for the segregation of canl by following the growth after replica plating to canavanine medium. For each of all 9 tetrads, it was found that one His, Ura, and Ile auxotrophic spore gave rise to a clone which was classified as resistant after 24 hours, while cells from a second spore needed two days to grow up. The two remaining spores were canavanine sensitive. The slowly emerging resistant cells were all coming from spores that were originally scored as $\mathrm{His}^{+}, \mathrm{Ile}^{+}$, and $\mathrm{Ura}^{+}$, but testing of the phenotypes of the cells that came up on canavanine showed that they had now become auxotrophic for all three nutrients. These resistant clones were thus all produced from disomic strains by mitotic chromosome loss of the $\mathrm{S}$. carlsbergensis CANI gene and subsequent selection on the canavanine plates. In summary, the results show that $C A N 1$ and URA3, HIS1 and ILVI are linked also in S. carlsbergensis and that strains IXX18 and IXX11 contain an additional chromosome from this species not recombining with the normal S. cerevisiae chromosome V.

Results from tetrad analysis of the two canavanine resistant isolates (IXX3 and C80-1607) are shown in Tables III and IV. In crosses involving the HISI tester strain (Table III), the segregation of HIS1 shows a significant number of $4: 0$ asci, while the rest of the chromosome $\mathrm{V}$ 
Table II. Tetrad analysis of two canavanine sensitive chromosome addition strains (crosses $M A T a^{+} / \mathrm{canI}^{+} / \mathrm{ura3}$ */his1 +/ilv1 +/rad3 ade2 cyh2 kar1 $\times$ MATa CAN1 ura3 his1 ilv1 rad3 trp1 leu2).

\begin{tabular}{|c|c|c|c|c|c|}
\hline \multicolumn{6}{|c|}{ IXX $18 \times 240380 \mathrm{~B}-55$} \\
\hline \multirow[t]{2}{*}{ Marker } & \multicolumn{5}{|c|}{ Segregation } \\
\hline & $4: 0$ & $3: 1$ & $2: 2$ & $1: 3$ & $0: 4$ \\
\hline HISI:hisl & & & 49 & & \\
\hline ILVI:ilvl & & & 49 & & \\
\hline URA3:ura3 & & & 49 & & \\
\hline$T R P 1 \cdot \operatorname{trpl}$ & & & 49 & & \\
\hline LEU2:leu2 & & & 49 & & \\
\hline ADE2:ade2 & & & 49 & & \\
\hline \multirow[t]{2}{*}{$M A T \mathbf{a}: M A T \alpha$} & & & 49 & & \\
\hline & & PD & NPD & TT & \\
\hline ILVI:HISI & & 49 & 0 & 0 & \\
\hline HIS1:URA3 & & 48 & 0 & 1 & \\
\hline URA3:TRPI & & 23 & 24 & 2 & \\
\hline \multicolumn{6}{|c|}{ IXX11 $\times 240380 \mathrm{~B}-55$} \\
\hline \multirow[t]{2}{*}{ Marker } & \multicolumn{5}{|c|}{ Segregation } \\
\hline & $4: 0$ & $3: 1$ & $2: 2$ & $1: 3$ & $0: 4$ \\
\hline HIS1:his1 & & & 16 & & \\
\hline URA3:ura3 & & & 16 & & \\
\hline LVI:HIVl & & & 16 & & \\
\hline ADE2:ade2 & & & 16 & & \\
\hline TRPl:trpI & & & 16 & & \\
\hline LEU2:len2 & & & 16 & & \\
\hline \multirow[t]{2}{*}{$M A T \mathbf{a}: M A T \alpha$} & & & 16 & & \\
\hline & & PD & NPD & TT & \\
\hline ILVI:HISI & & 16 & 0 & 0 & \\
\hline$H I S 1 \cdot U R A 3$ & & 16 & 0 & 0 & \\
\hline URA3:TRPI & & 11 & 5 & 0 & \\
\hline
\end{tabular}

markers segregate normally. This shows that the diploid contained two copies of HISl (one from 040480I-47 and one from S. carlsbergensis) and one hisl (from the karl recipient C80-II-17). The distribution of tetrad types shown in Tables III and IV makes it clear that the HISI, URA3, $I L V 1$, and $R A D 3$ wild-type genes introduced from $S$. carlsbergensis are indeed linked. However, in this case the introduced chromosome is able to recombine with a S. cerevisiae chromosome. The genetic distances observed between these genes are similar to what is observed in crosses between laboratory strains (18) and fit also well with the distances found in the crosses performed to construct the recipient and tester strains used in this study. It should be pointed out that these distances are determined in a trisomic diploid. As was found in the crosses of the two canavanine sensitive, primary isolates, the canl gene was difficult to score on the canavanine medium. In this case we suspected the presence of two copies of the canl gene in strains IXX3 and C80-1607, as they express the recessive phenotype (canl) of the recipient strain. Complete absence of a CANI locus as a result of e.g. a translocation would also result in a canavanine resistant chromosome addition strain under the present conditions. Segregation of two canl and one $C A N 1$ gene in the trisomic diploids would result in a predominantly $2: 2$ 
Table 1II. Tetrad analysis of two canavanine resistant chromosome addition strains (crosses MATa can1/can1 +/ura3 +/his1 +/ilv1 +/rad3 ade2 cyh2 kar1 × MAT a CAN1 ura3 HIS1 ilv1 rad3 trp1 leu2)

IXX3 × 040380I-47

Marker

HISI:hisl

ILVI:ilvI

URA3.ura3

RAD3:rad3

TRP1:trp1

LEU2.leu2

ADE2:ade2

URA3:ILVI

ILVI:RAD3

URA3:TRPI

C80-1607 $\times 040380 \mathrm{I}-47$

Marker

HISI:hisl

ILVI:ilvI

URA3:ura3

RAD3:rad3

TRPl:trpl

ADE2 ade2

URA3'ILVI

ILVI:RAD3

URA3:TRP1
4:0

3

PD

3

2

2

4:0

4

$3: 1$

7

PD

4

3

4
Segregation

3

$2: 2$
3
9
9
8
9
9
9

$1: 3$

0:4

1

9

9

$\begin{array}{cr}\text { NPD } & \text { TT } \\ 1 & 5 \\ 1 & 5 \\ 4 & 3\end{array}$

Segregation

$\begin{array}{rrr}2: 2 & 1: 3 & 0: 4 \\ 4 & & \\ 15 & & \\ 15 & & \\ 13 & 2 & \\ 14 & & \\ 15 & & \end{array}$

$\begin{array}{cr}\text { NPD } & \text { TT } \\ 2 & 9 \\ 0 & 10 \\ 7 & 3\end{array}$

distribution of sensitive to resistant colonies. This was also observed in most tetrads (Table IV), but this cross also produced many tetrads showing the ratio of one $\operatorname{Can}^{\mathrm{R}}$ to three $\mathrm{Can}^{\mathrm{S}}$, as well as asci with four $\mathrm{Can}^{\mathrm{s}}$ spores. Such a segregation should not be compatible with the hypothesis of the presence of two canl genes. However, the canavanine resistance introduced from S. carlsbergensis is not as strong as the one from S. cerevisiae. Therefore, some slowly growing can I colonies will be scored as $\mathrm{Can}^{\mathrm{s}}$, explaining the presence of the 4:0 and 3:1 asci. The distribution of tetrad types for CAN1-URA3 in the cross described in Table IV does not seem to indicate linkage of the genes as the number of NPD tetrads (2 $\left.\mathrm{Ura}^{+} \mathrm{Can}^{\mathrm{S}}: 2 \mathrm{UraCan}^{\mathrm{R}}\right)$ is too high. However, in this particular cross we fol- lowed the segregation of two S. cerevisiae chromosomes, marked with canl ura3 (recipient) and CANI ura3 (tester), together with a $\mathrm{S}$. carlsbergensis chromosome carrying URA3 and, presumably, can1. With this distribution of genes between the different chromosomes, NPD tetrads will appear not only as a consequence of double cross-over, but also when for instance the S. carlsbergensis chromosome in the first meiotic division segregates together with a $\mathrm{S}$. cerevisiae chromosome carrying $C A N 1$. Although the meiotic analysis of IXX3 and C80-1607 did not prove that canl and $U R A 3$ of S. carlsbergensis origin were linked, we consider this to be the most likely explanation for the high number of $\mathrm{Can}^{\mathrm{R}}$ colonies obtained after transfer of chromosome V from $\mathrm{S}$. carlsbergensis. 
Table IV. Tetrad analysis of the canavanine resistant chromosome addition strain C80-1607 after crossing to 240380B-55 (MATa CAN1 ura3 his1 ilv1 rad3 trp1 leu2).

\begin{tabular}{|c|c|c|c|c|c|}
\hline \multirow[t]{2}{*}{ Marker } & \multicolumn{5}{|c|}{ Segregation } \\
\hline & $4: 0$ & $3: 1$ & $2: 2$ & $1: 3$ & $0: 4$ \\
\hline HISI:hisl & & & 58 & 4 & \\
\hline ILVI.ilvI & & & 61 & 1 & \\
\hline URA3:ura3 & & 1 & 60 & 1 & \\
\hline RAD3:rad3 & & 2 & 57 & 3 & \\
\hline CAN1:can1 & 4 & 9 & 47 & 2 & \\
\hline TRPI:trpI & & & 62 & & \\
\hline LEU2:leu2 & & & 62 & & \\
\hline ADE2:ade2 & & & 62 & & \\
\hline \multirow[t]{2}{*}{$M A T \mathbf{a} . M A T \alpha$} & & & 62 & & \\
\hline & & PD & NPD & TT & $\mathrm{cM}^{\mathrm{a}}$ \\
\hline HISI:ILVI & & 37 & 0 & 21 & 18 \\
\hline HISI:URA3 & & 30 & 7 & 22 & 54 \\
\hline$I L V I: R A D 3$ & & 27 & 3 & 26 & 39 \\
\hline URA3:CAN1 & & 12 & 9 & 26 & n.l. \\
\hline URA3:TRPI & & 26 & 23 & 11 & $9^{b}$ \\
\hline
\end{tabular}

In summary, the meiotic analysis of colonies carrying $H I S I, U R A 3$, and $I L V I$ from the brewing strain showed that they are disomic for chromosome $\mathrm{V}$ and that two different types of this chromosome are present in S. carlsbergensis.

\subsection{Construction and tetrad analysis of chromosome substitution strains}

In order to establish if the two different types of chromosome $\mathrm{V}$ present in $\mathrm{S}$. carlsbergensis C80-CG1 10 are functionally homologous to the $\mathrm{S}$. cerevisiae chromosome $\mathrm{V}$ and to be able to measure genetic distances in euploid strains, we constructed strains where the normal S. cerevisiae chromosome $\mathrm{V}$ was substituted by a chromosome from $S$. carlsbergensis. The strategy utilized the location of the $C A N 1$ gene on chromosome $\mathrm{V}$. The disomic strain IXX18 contains a mutant can 1 gene from the recipient strain in addition to a wild-type $C A N 1$ gene from $\mathrm{S}$. carlsbergensis. As the gene giving resistance to canavanine is recessive, IXX18 is sensitive, but resistant subclones will be produced if the $C A N I$ gene is lost by either mitotic recombination or chromosome loss. Thus, if a colony is replica plated to canavanine medium, no growth is seen after 24 hours of incubation but after a further 24 hours, the few cells that have lost the carlsbergensis chromosome (about 1\%) will have gone through a sufficient number of cell divisions to allow the detection of growth. If instead the canl gene had been lost in the cell that formed the original colony, resistant growth can only appear in the much rarer cases of a mutation. To screen for the appearance of a chromosome substitution strain by the spontaneous loss of the canl carrying S. cerevisiae chromosome V, IXX18 was grown in YPD to late logarithmic phase and plated on YPD at a density of approximately 400 colonies per plate. After three days of growth the colonies were replica plated to canavanine medium. Colonies that did not give rise to growth after 4 days on canavanine were selected and retested to confirm the lack of ability to produce $\mathrm{Can}^{\mathrm{R}}$ papillae. One such isolate, C80-1609 (see Figure 1), was crossed to tester strains that were wild-type for either HISI or $I L V I$ and a tetrad analysis was carried out. 
Table V. Tetrad analysis of the canavanine sensitive chromosome V substitution strain C80-1609 (MATa CANI URA3 HIS1 ILV1 RAD3 ade2 cyh2 kar1).

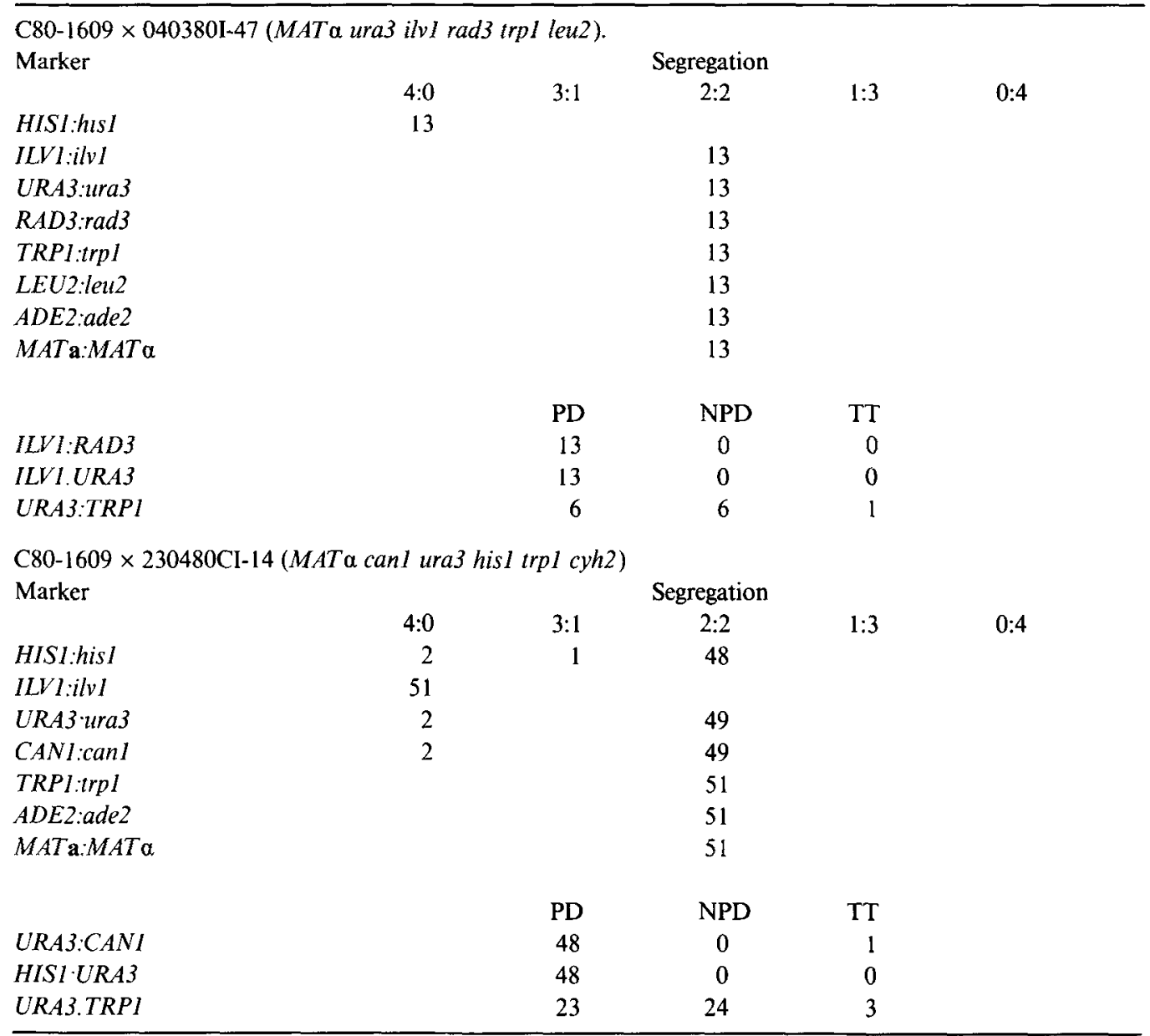

Both these genes are located on the right arm of chromosome $\mathrm{V}$ while $C A N 1$ is on the left arm. The complete absence of segregation of hisl or ilvI in these crosses (Table V) demonstrates that chromosome $\mathrm{V}$ of the karl recipient strain C80-II-17 has indeed been lost. Thus, strain C80-1609 is a substitution strain with a $\mathrm{S}$. carlsbergensis chromosome instead of a S. cerevisiae chromosome $\mathrm{V}$. The strain grows normally on complete, as well as minimal medium, showing that all essential genes located on chromosome $\mathrm{V}$ are also present on the substituting chromosome. The presence of $R A D 3$ was not investigated in the disomic strain IXX18, but the data shown in Table $\mathrm{V}$ (upper cross) and
Table VI demonstrate that also this chromosome $\mathrm{V}$ gene is present and functional on the non-recombining chromosome $\mathrm{V}$ of S. carlsbergensis.

C80-1609 is mitotically unstable and has a strong tendency to produce clones with two chromosomes $\mathrm{V}$. This is seen in the lower cross presented in Table $\mathrm{V}$, where two out of the 51 analysed asci are found to segregate 4:0 for the chromosome $\mathrm{V}$ markers because of the presence of two $\mathrm{S}$. carlsbergensis chromosomes in the diploid. Possibly, some function important for growth rate or viability is encoded by a gene located on chromosome $\mathrm{V}$ and the $\mathrm{S}$. carlsbergensis gene provides limiting function if it is not 


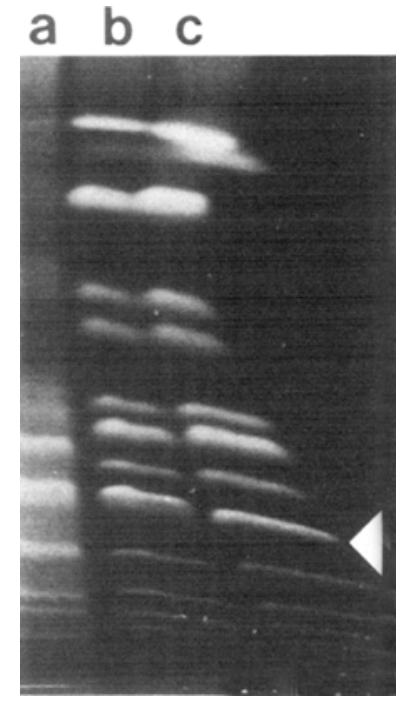

Figure 2. Electrophoretic chromosome separation of DNA from S. carlsbergensis and S. cerevisiae strains. DNA from S. carlsbergensis strain C80-CG7 (lane a), the chromosome substitution strain C80-1609 (lane b) and the S. cerevisiae strain C80-II-17 (lane c) was extracted and separated according to the method of CARLE and OLSON (3). An arrow marks the position of chromosome V and VIII in S. cerevisiae (3).

present in double dosis.

An electrophoretic chromosome separation according to CARLE and OLSON (3) was made with DNA from strains C80-CG7, C80-1609 and C80-II-17 (Figure 2). Although the DNA of the $S$. carlsbergensis strain has not been especially well resolved in this experiment, it is evident from the figure that several of the chromosomal bands have a different mobility compared to those of the S. cerevisiae strain C80-II-17. As expected, the band patterns of the latter strain and the substitution strain (C80-1609) are almost completely identical. Only in the case of the band representing chromosomes $\mathrm{V}$ and VIII (3), indicated by an arrow in Figure 2, is it possible to observe a difference. Comparing the band pattern of all three strains, it is evident that chromosome $\mathrm{V}$ of $\mathrm{S}$. carlsbergensis (present in C80-CG7 and C80-1609) has a slightly lower electrophoretic mobility than chromosome $\mathrm{V}$ of $\mathrm{S}$. cerevisiae. Furthermore, the intensity of the chromosome $\mathrm{V}$ band of the substitution strain is consistent with the notion that this chromosome is present in two copies. Chromosome VIII of S. cerevisiae is seen to migrate slightly faster than the carlsbergensis chromosome $\mathrm{V}$ in the substitution strain.

The isolate of C80-1609 in our strain collection was later found to have become disomic for chromosome $\mathrm{V}$. We have now constructed a new strain monosomic for chromosome $\mathrm{V}$ by crossing C80-1609 to a canavanine resistant strain (strain 230480-CI-14). After sporulation and dissection, tetrads with four living spores were selected and tested for auxotrophic requirements and canavanine resistance. As expected, all four spores were $\mathrm{His}^{+}, \mathrm{Ura}^{+}, \mathrm{Ile}^{+}$, and canavanine sensitive after 24 hours of incubation. However, further incubation of the canavanine containing plates showed that two of the spores of each tetrad produced resistant papillae. The papillae were His, Ura, and Ilv and were thus signalling that these two spores, in addition to the $\mathrm{S}$. carlsbergensis chromosome $\mathrm{V}$ from $\mathrm{C} 80$ 1609 , also contained the chromosome $\mathrm{V}$ of strain 230480-CI-14. The other two spores of the tetrads did not, even after prolonged incubation, produce any canavanine resistant growth and were therefore assumed to be monosomic for chromosome V of S. carlsbergensis. Subsequent tetrad analysis confirmed this notion and showed that the new strains retained the properties of the original isolate of C80-1609, including the pronounced mitotic instability (data not shown).

The linkage data shown in Tables $\mathrm{V}$ and VI agree completely with what was found for the disomic parental strain IXX18, in that all chromosome $\mathrm{V}$ markers appear tightly linked. Among the 87 tetrads of the three crosses, only one ascus is found with recombination between the lager yeast and the laboratory yeast chromosomes. This low frequency of recombination is not due to the presence of inversions in the $\mathbf{S}$. carlsbergensis chromosome as the spore viability in each of the crosses was between 80 and $90 \%$.

The $C A N 1$ gene was also used for the construction of a substitution with the recombining chromosome. The strains IXX3 and C80-1607, which harbor this chromosome, show a canavanine resistant phenotype, as neither the recipient strain nor the recombining $S$. carlsbergensis 
Table VI. Tetrad analysis of the canavanine sensitive chromosome $\mathrm{V}$ substitution strain $\mathrm{C80}-1609$ after crossing to 0403801-56 (MAT a CAN1 ura3 his1 ilv] rad3 leu2).

\begin{tabular}{lcccc}
\hline Marker & $4: 0$ & $3: 1$ & Segregation & \\
& & $2: 2$ & $1: 3$ & $0: 4$ \\
HISI:hisl & & 23 & & \\
ILVI:ilvl & & 23 & \\
URA3:ura3 & & 23 & \\
RAD3:rad3 & & 23 & \\
LEU2:leu2 & & 21 & 2 \\
ADE2:ade2 & & 23 & \\
MAT:MATa & & 23 & \\
& PD & NPD & TT \\
HISI:ILVI & 23 & & \\
ILVI:RAD3 & 23 & & \\
HISI:URA3 & 23 & & \\
URA3:LEU2 & 9 & 8 & 4 \\
\hline
\end{tabular}

chromosome carry information for a functional arginine permease. To obtain a disomic strain heterozygous for can1, we performed a new chromosome transfer experiment with a recipient strain (080182B-51) which was similar to the strain used in the first experiment, but this time canavanine sensitive. Again, red, cycloheximide resistant, $\mathrm{His}^{+}, \mathrm{Ura}^{+}$, and $\mathrm{Ile}^{+}$colonies were selected. Approximately $50 \%$ of these colonies gave spontaneously rise to canavanine resistant papillae after growth on canavanine medium, indicating that they contained cells with a canl gene from S. carlsbergensis. Ten such colonies were picked and grown to early stationary phase and plated on YPD. After 3 days of growth at 30 ${ }^{\circ} \mathrm{C}$ they were replica plated to canavanine medi$u m$ and after 24 hours of incubation the plates were inspected for the appearance of colonies with vigorous growth. All ten selected clones produced at least one such colony which was resistant to canavanine and one colony from each clone was purified and crossed to strain 040380I-47. Tetrad analysis showed that four of the isolates were chromosome substitution strains that had become canavanine resistant by loss of the $\mathrm{S}$. cerevisiae chromosome with $C A N 1$. Two of the remaining six strains could not be analysed because of poor spore viability. The rest were chromosome addition strains which probably had become resistant by mitotic recombination leading to homozygosity for canl. An extended tetrad analysis was carried out on one of the chromosome substitution strains (strain 250382-4AI) (see Figure 1). As can be seen in Table VII (upper cross) no segregation of hisl is seen when 250383-4AJ is crossed to a tester strain that is wild-type for this gene. As HISI and CANI map on each side of the centromere, this provides strong evidence for the loss of chromosome $V$ of the recipient strain. The results from a cross to a tester strain, recessive for all five chromosome $\mathrm{V}$ markers used in this study, are given in the lower half of Table VII. From the data in the table it can be seen that the distances measured between chromosome $\mathrm{V}$ loci in strain 250382-4A-I resemble the distances obtained in pure $\mathrm{S}$. cerevisiae crosses. Comparing the results obtained from the disomic strain C80-1607 and the substitution strain, a considerable difference in the region ILVI-RAD3 (Tables VII and IV) is seen. While no linkage can be detected between these markers in the substitution strain (distance $>50$ $\mathrm{cM}$ ), the low number of NPD tetrads in the case of the chromosome addition strain clearly indicates that the genes are on the same chromosome. The other gene distances are not influenced to any considerable extent by the presence of a third chromosome. 
Table VII. Tetrad analysis of the canavanine resistant chromosome $V$ substitution strain 250382-4A-I (MAT a canI URA3 HIS1 ILV1 RAD3 ade2 cyh2 kar1).

\begin{tabular}{|c|c|c|c|c|c|}
\hline \multirow[t]{2}{*}{ Marker } & \multicolumn{5}{|c|}{ Segregation } \\
\hline & $4: 0$ & $3: 1$ & $2: 2$ & $1: 3$ & $0: 4$ \\
\hline HISI:hisl & 50 & & & & \\
\hline ILV1:ilvl & & 2 & 48 & & \\
\hline URA3:ura3 & & & 50 & & \\
\hline CAN1 canl & & 1 & 46 & 3 & \\
\hline$R A D 3: \operatorname{rad} 3$ & & & 50 & & \\
\hline LEU2:leu2 & & & 50 & & \\
\hline ADE2.adez & & & 50 & & \\
\hline & & PD & NPD & TT & $\mathrm{cM}^{\mathrm{a}}$ \\
\hline URA3:CANI & & 20 & 1 & 25 & 34 \\
\hline URA3:ILVI & & 12 & 4 & 32 & 58 \\
\hline ILV3:RAD3 & & 7 & 8 & 32 & n.l. \\
\hline URA3:TRPI & & 23 & 21 & 6 & $6^{b}$ \\
\hline
\end{tabular}

250382-4A-I × 240380B-55 (MATa ura3 his1 ilv1 rad3 trp1 leu2)

Marker

HIS1:his1

ILVI:ilv1

URA3:ura3

CANI:can1

RAD3:rad3

TRPI:trpI

LEU2:leu2

$A D E 2$ ade2

MATa:MATa

HIS1:ILVI

ILV1:RAD3

HIS1:URA3

URA3:CANI

URA3:TRPI

4:0

:0

n.l. = no linkage detectable

a'Genetic distances were calculated according to the formula of PerkINS (23).

${ }^{b}$ Distance between $U R A 3$ and the centromere.

\subsection{Molecular analysis of four loci on chromosome $\mathrm{V}$}

In two earlier publications $(9,21)$ we have shown that the absence of recombination between a region of chromosome III from $S$. carlsbergensis strain 244 and standard laboratory strains is correlated with nucleotide sequence inhomology. In contrast, genes mapping in the region where recombination takes place are indistinguishable from the genes of the laboratory strains. To investigate whether there is an analogous difference between the non-recombining and recombining chromosomes $\mathrm{V}$ of S. carlsbergensis we analysed four different loci, ilv1, ura3, cyc7, and canl, by molecular hybridization according to the technique of SOUTHERN (28). DNA from strains C80-II-17 (recipient), 244 (S. carlsbergensis), C80-1609 
CAN1

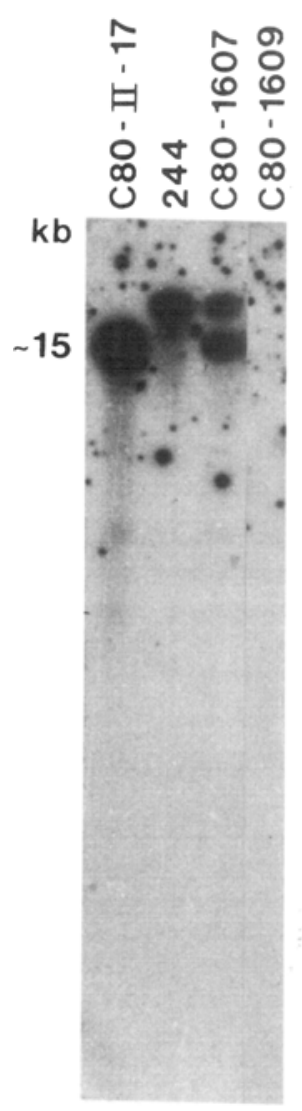

(a)
CYC7

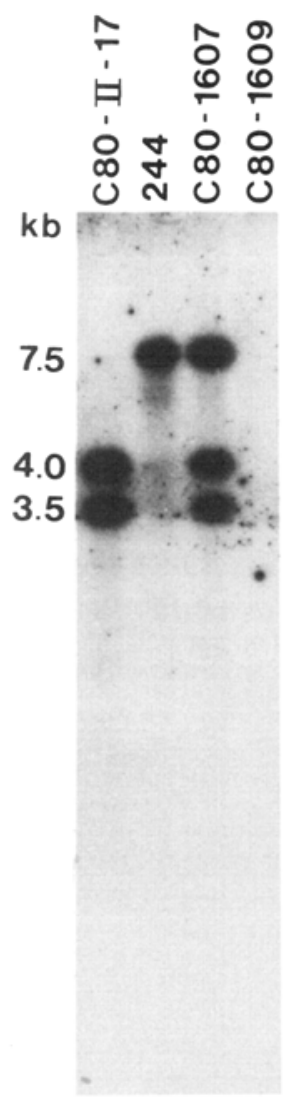

(b)
URA3

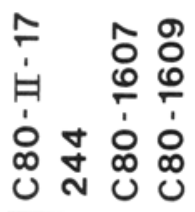

kb

$k b$

ILV1

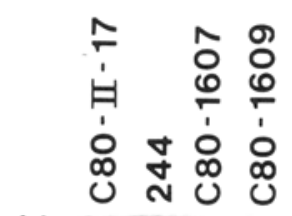

U

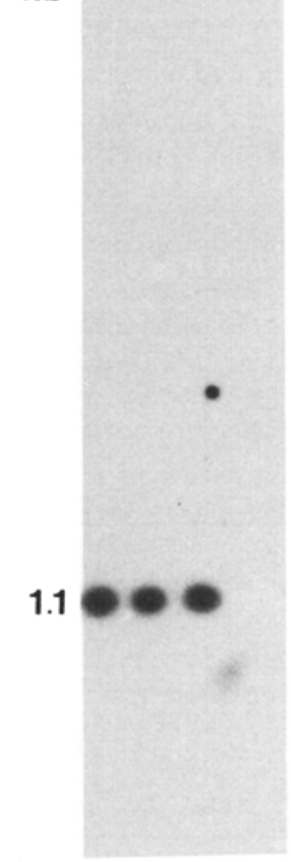

(c)
4.2

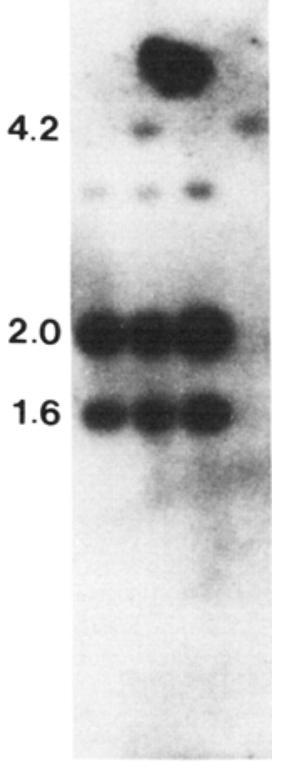

(d)

Figure 3. Molecular hybridization analysis of four chromosome V genes. DNA from strains 244 (S. carlsbergensis), C80-II-17 ( karl recipient S. cerevisiae), C80-1607 (chromosome addition strain with recombining chromosome) and C80-1609 (chromosome substitution strain with non-recombining chromosome) was digested with restriction enzymes $\mathrm{EcoRI}$ ( $a$ and d) or HindIII ( $b$ and $c$ ). The resulting fragments were separated by electrophoresis, transferred to nitrocellulose membranes, and hybridized to the following ${ }^{32} \mathrm{P}$-labelled probes:(a) $C A N I$, a $0.7 \mathrm{~kb}$ BamHI-EcoRI fragment subcloned from plasmid TLC-1 (2). (b) URA3 a, $1.1 \mathrm{~kb}$ HindIII fragment from plasmid MB1068. (c) CYC7, plasmid pAB25 (17). (d) $I L V 1$, a $6.1 \mathrm{~kb}$ HindIII-Sall fragment from plasmid pC519.

Hybridization was in $3 \times \mathrm{SSC}$ at $68^{\circ} \mathrm{C}$ followed by washing in $0.1 \times \mathrm{SSC}$ at the same temperature.

(substitution strain with non-recombining chromosome), and C80-1607 (addition strain with recombining chromosome) was cut with restriction endonucleases EcoRI, HindIII, BamHI, and PstI. After agarose gel electrophoresis the fragments were transferred to nitrocellulose filters and analysed by molecular hybridization to in vitro ${ }^{32} \mathrm{P}$-labelled probes. For the $i l v l$ locus the two adjacent fragments (3.2 kb HindIII-HindIII and 2.9 HindIII-Sall) prepared from plasmid pC519 (see Figure 4) were used as probe. The probe for the ura3 locus was a $1.1 \mathrm{~kb}$ HindIII fragment prepared from plasmid MB1068 obtained from T. Petes (University of Chicago, Illinois, USA). The $c y c 7$ locus was analysed with plasmid pAB25 (kindly supplied by F. SHER- 


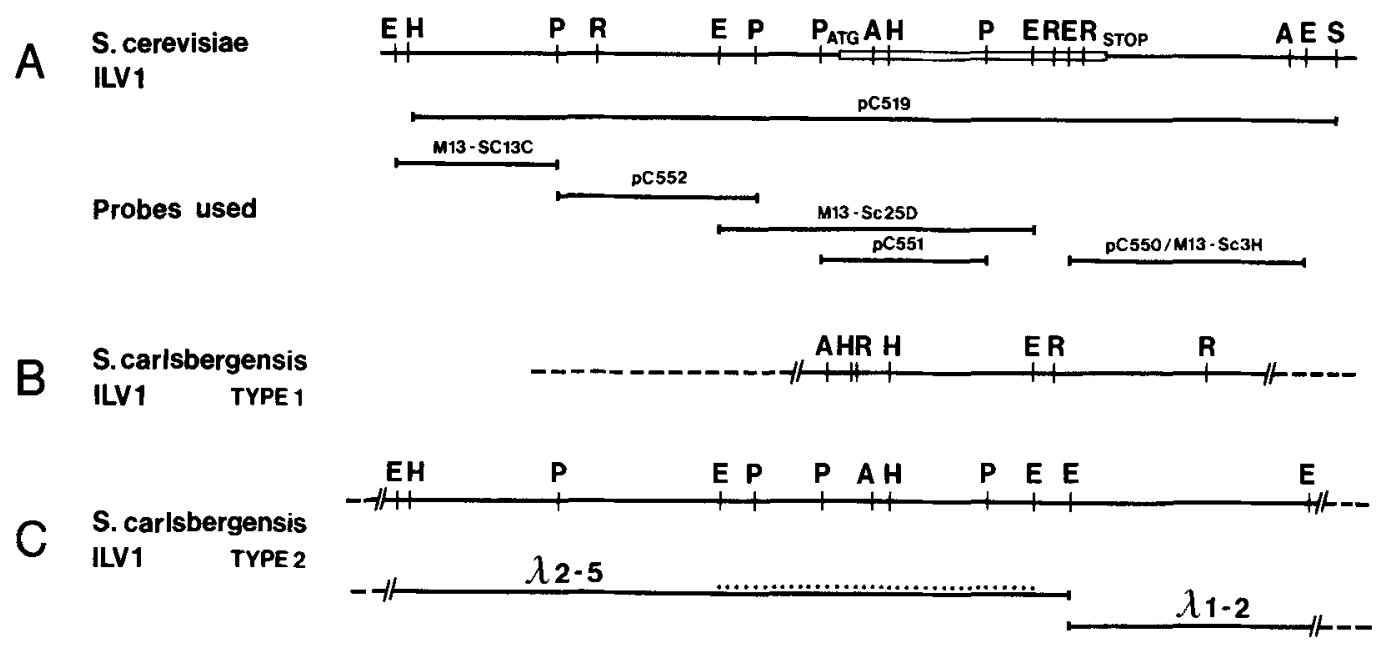

Figure 4. Restriction endonuclease map of the ILVI genes of S. carlsbergensis and S. cerevisiae.

(A): The $I L V I$ gene of S. cerevisiae (14). The box shows the coding region of the gene. Below the gene are shown the size and location of the probes used for identifying recombinant $\lambda$ phages and for the localization of the coding region in plasmid pCI-1 as well as in the recombinant phages $\lambda 1-2$ and $\lambda 2-5$.

(B): The ILVI allele (type 1) found on the homoeologous chromosome $\mathrm{V}$ of $\mathrm{S}$. carlsbergensis and cloned in plasmid $\mathrm{pCl}-1$ and phage $\lambda \mathrm{L} 47$-R6. No PstI sites are present in the depicted region.

(C): The ILVI allele (type 2) found on the homologous chromosome $\mathrm{V}$ of S. carlsbergensis and cloned in the phages $\lambda 1-2$ and $\lambda 2-5$. The extent of these two phages covering the $I L V 1$ region is depicted below the restriction site map. The region of $\lambda 2-5$ which was mapped with enzymes AccI, AhaIII, AvaI, FokI, PvuII and Xhol is marked by a stippled line. The two phages, $\lambda 1-2$ and $\lambda 2-5$, were not mapped with the enzyme EcoRV.

The following signatures are used: $\mathrm{A}=\mathrm{AccI} ; \mathrm{E}=\mathrm{EcoRI} ; \mathrm{R}=\mathrm{EcoRV} ; \mathrm{H}=$ HindIII $\mathrm{P}=\mathrm{PstI} ; \mathrm{S}=$ Sall. No difference in restriction enzyme sites were detected between the cloned fragments of $S$. carlsbergensis $I L V I$ type 2 and the S. cerevisiae gene.

MAN, University of Rochester, New York, USA). This plasmid contains the $C Y C 7$ gene on a 7.4 kb fragment in pBR322 (17). Finally, a subcloned $0.7 \mathrm{~kb}$ BamHI-EcoRI fragment from plasmid TLC-1 (2) (kindly supplied by J.R. BroACH, Princeton University, New Jersey, USA) was used for the can1 region. The results in Figure 3 show that all the probes hybridize very poorly with DNA from strain $\mathrm{C} 80-1609$ at the chosen stringency (hybridization at $68^{\circ} \mathrm{C}$ in $3 \times$ SSC, washings in $0.1 \times$ SSC at the same temperature). Only in the case of the $i l v 1$ probe (Figure 3d), a faint band of $4.2 \mathrm{~kb}$ can be seen. The same results are obtained with the three other restriction enzymes used in the experiment (data not shown). In contrast, strong hybridization is obtained with DNA from the three other strains. The patterns obtained for strain 244 probed with ilvl DNA contain bands identical to those of the recipient strain in addition to the faint bands specific for the non-recombining $\mathrm{S}$. carlsbergensis chromosome. In the chromosome addition strain C801607 , only the $S$. cerevisiae like pattern is observed. As mentioned above, the ura 3 probe does not hybridize to strain C80-1609 and the pattern observed with strains 244 and C80-1607 is identical to the pattern of S. cerevisiae for all four enzymes tested. In the case of the $c y c 7$ and can1 loci, the autoradiograms disclose a slightly altered nucleotide sequence in the $S$. cerevisiae like chromosome of strain 244 (Figures $3 \mathrm{a}$ and b). Thus, a HindIII and a PstI site were found to be absent in the region covered by the $c y c 7$ probe, resulting in the formation of a larger fragment. Polymorphism for the HindIII site has been reported in genetic standard strains (17). As expected, the chromosome addition strain 
C80-1607 shows the pattern of the recipient strain as well as that of S. carlsbergensis. In the case of canl, a difference in restriction enzyme fragment length was observed between the recipient and strain 244 for the enzymes EcoRI (Figure 3a) and HindIII (data not shown). To summarize, the results from the molecular hybridization experiments confirm the genetic data, showing the presence in S. carlsbergensis of two structurally different chromosomes $\mathrm{V}$.

\subsection{Molecular cloning of the $I L V 1$ gene of $\mathrm{S}$. carlsbergensis}

To be able to get a more precise knowledge of the structure of the different wild-type alleles of a gene located on chromosome $\mathrm{V}$, we cloned the two ILVI alleles of strain 244. In a first attempt, DNA from this strain was partially digested with EcoRI and ligated into the $\lambda$-EcoRI vector NM781 (19). Two recombinant phages, $\lambda 1-2$ and $\lambda 2-5$, respectively, were recovered with sequences homologous to the S. cerevisiae ILVI probe pC519 (see Figure 4). One of the recombinant phages, $\lambda 1-2$ (Figure 4C) was found to have, in its insert, a $1.5 \mathrm{~kb}$ EcoRI fragment equivalent in size and homologous to the EcoRI fragment containing the 3' end of the ILVI gene of S. cerevisiae (24). Like in S. cerevisiae, this fragment did not contain any restriction endonuclease sites for the enzymes PstI and HindIII. The other phage, $\lambda 2-5$ (Figure 4C), contained an insert that covered the rest of the gene and several kb upstream of the translation startpoint. This clone contains three EcoRI-HindIII fragments which hybridize to pC519. They are identical, both in size and in the positions of four PstI sites, to three contiguous EcoRI - HindIII fragments of $I L V I$ of S. cerevisiae (14). Two of the three EcoRI - HindIII fragments cover almost the entire coding region of the S. cerevisiae gene. They were isolated by gel electrophoresis and subjected to restriction enzyme mapping with AccI, AhaIII, AvaI, FokI, PvuII, and Xhol. In this region a total of 16 sites for these enzymes are present in the $S$. cerevisiae gene as determined by sequencing (14). All 16 sites were found to be present in the two fragments. Thus, strain 244 contains one allele of the ILVI gene which is identical or very closely related to the $\mathrm{S}$. cerevisiae allele. The approximate position of the coding region at the $S$. carlsbergensis $I L V I$ gene in Figure $4 \mathrm{C}$ was localized by a Southern analysis (28): $\lambda 1-2$ and $\lambda 2-5$ were treated with the restriction enzymes EcoRI, HindIII, and PstI in single or double digestion and probed with three different ${ }^{32} \mathrm{P}$-labelled M13-ILVI DNAs. The location of the three probes, M13-Sc13C, M13-Sc25D, and $\mathrm{M} 13-\mathrm{Sc} 3 \mathrm{H}$ are depicted in Figure 4 (14). As expected, M13-Sc25D, which contains most of the $\mathrm{S}$. cerevisiae $I L V I$ coding region, hybridized to all restriction enzyme fragments with endpoints within the $2.1 \mathrm{~kb}$ EcoRI fragment of $\lambda 2-5$.

The other $I L V I$ allele of strain 244 was cloned from the substitution strain C80-1609. Partially MboI digested DNA was ligated to purified BamHI digested $\lambda L 47$ arms $(15,16)$. One re'combinant phage, $\lambda \mathrm{L} 47-\mathrm{R} 6$ was isolated with an insert of approximately $18 \mathrm{~kb}$ containing the $I L V I$ gene as judged by hybridization to pC519. Further analysis of the insert in this phage showed that the gene was located on an approximately $12 \mathrm{~kb}$ BamHI fragment. This fragment was subcloned in plasmid pC508 (pBR325$T R P 1-A R S 1$ ), and the resulting plasmid, pCI-1, was able to transform a $S$. cerevisiae $i l v 1$ strain (C81-1431) to isoleucine prototrophy with high frequency. Thus, the entire gene is contained on the BamHI fragment. A map of the recognition sites for the enzymes AccI, EcoRI, EcoRV, HindIII, and PstI in the gene is shown in Figure 4B. Colinearity of the type $1 I L V I$ allele as drawn in Figure 4B was established by probing BamHI, HindIII, EcoRI, and PstI restriction enzyme digests of pCI-1 with labelled pC552, pC551, and $\mathrm{pC} 550$ (10) (see Figure 4). The map has been finally positioned relative to the $S$. cerevisiae gene from the conserved locations of an EcoRI, a HindIII, and an EcoRV site in the nucleotide sequence (C. GJeRmansen, in preparation).

\section{DISCUSSION}

The genetic and molecular analysis of the strains obtained from the single chromosome transfer experiments clearly demonstrates the presence of two different chromosomes $\mathrm{V}$ in $\mathrm{S}$. carlsbergensis. One of these chromosomes appears to be homologous to chromosome $\mathrm{V}$ of 
laboratory strains in that genetic recombination between them is unimpaired. The data from the molecular hybridization experiments confirm the great similarity between these two chromosomes. It is unexpected that there are similar distances between the markers observed with the recombining chromosome $\mathrm{V}$ whether it is analysed in a disomic or trisomic situation, i.e. together with one or two homologous S. cerevisiae chromosomes: If it is assumed that in a trisomic strain the total probability of physical exchange between two genes is the same as in a normal diploid, one would expect to register a reduced frequency of recombination in our experimental set up, as recombination between the two $S$. cerevisiae chromosomes can not be seen (both are marked with recessive alleles). As the recombination frequency in the canl-ilv1 region is normal, it is as if genetic exchange is stimulated in our trisomic strains, with the homologous chromosome V from S. carlsbergensis. Such stimulation has previously been found in trisomic $S$. cerevisiae strains by SHAFFER et al. (27). Only in the case of the region ilv1-rad 3 do we observe a strong map contraction when measured in a trisomic strain. Possibly this reflects a different structure in the region leading to a preferential pairing between the two S. cerevisiae homologues and thereby a reduced possibility for the $S$. carlsbergensis chromosome to recombine with one of the $S$. cerevisiae chromosomes.

The other chromosome $\mathrm{V}$ of $\mathrm{S}$. carlsbergensis is also functional in the recipient strains, but quite different in physical structure as well as in genetic properties. This homoeologous chromosome does not recombine with the laboratory strain chromosome $\mathrm{V}$ and the molecular analysis shows that its nucleotide sequence is different. Since it is generally believed that chromosome pairing and crossing-over are needed for proper disjunction at meiosis, it is noteworthy that a high spore viability is obtained in crosses involving a strain carrying the homoeologous chromosome and genetic standard strains. Possibly, pairing and chiasma formation take place outside the most distal markers ( $\mathrm{rad} 3$ and $\mathrm{canl}$ ) used in this investigation. In the case of chromosome III from S. carlsbergensis, genetic recombination with $\mathrm{S}$. cerevisiae chromosome III only takes place in a distal region of the right arm (21) where the nucleotide sequence is homologous to the S. cerevisiae chromosome (9). In spite of the reduced recombination between these chromosomes disjunction seems to be unimpaired as judged by the high frequency of asci with 3 or 4 viable spores (21). That only a small region of homology is needed for proper disjunction of chromosomes has been demonstrated for the mammalian sex chromosomes (26). Moreover, recombination takes place in this homologous region with very high frequency (26). Another possibility is that, if just a single pair of chromosomes does not recombine, they can disjoin properly. D. DAWSON and J. SzOSTAK (personal communication) have found that in vitro constructed minichromosomes with little homology can disjoin efficiently. Such a phenomenon may be related to distributive pairing in Drosophila (8). As was the case with chromosome III absence of recombination in S. carlsbergensis chromosome $\mathrm{V}$ is correlated with a difference in nucleotide sequence between the involved chromosomes. The type $1 \mathrm{ILVI}$ gene in plasmid pCI-1 has been sequenced (C. GJERMANSEN, in preparation). In the coding region the homology with the $\mathrm{S}$. cerevisiae gene is approximately $80 \%$, with stretches of up to 29 nucleotides of perfect homology. The results of the molecular hybridization with $C A N 1, C Y C 7$, and $U R A 3$ suggest that a similar degree of homology is found also in the rest of the chromosome. Apparently, this is not enough to promote meiotic recombination to any reasonable level. It is unknown whether the absence of recombination is caused by reduced or absent synapsis of the chromosomes, or by a hindrance in formation of sufficiently long stretches of heteroduplex DNA.

The presence of a pair of homoeologous chromosomes $\mathrm{V}$ in $\mathrm{S}$. carlsbergensis resembles the situation described for chromosome III $(9$, 21). In the present study, genetic and molecular data have shown the presence of two different chromosomes, one which is $\mathrm{S}$. cerevisiae like, and one which is so structurally different that no recombination takes place over the entire known genetic map. Such homoeologous pairs of chromosomes have also been found for chromosomes XII and XIII (25) as well as for 
chromosome VII (unpublished data) and $\mathrm{X}$ (G.P. CASEY, Carlsberg Res. Commun., this issue). All these observations agree with our earlier proposition that the Carlsberg lager yeast is composed of two different Saccharomyces genomes $(22,25)$, and that the low degree of recombination between its set of homoeologous chromosomes could be a cause of improper disjunction at meiosis and the production of aneuploid spores with low viability.

\section{ACKNOWLEDGEMENTS}

We are grateful to J.R. BROACH, T.D. PETES, and F. SHERMAN for providing us with relevant cloned S. cerevisiae genes. D. VON WETTSTEIN is thanked for continuous interest and stimulating discussions and also for critical reading of the manuscript. JANNE V. HANSEN, KIRSTEN SCHULZ, and GITTE BANK provided skilful technical assistance. The electrophoretic karyotyping was carried out by M.C. K.-B. in the laboratory of G.R. FINK (Whitehead Institute) to whom we are indebted for hospitality and support. POUL ERIKSEN and NinA RASMUSSEN are thanked for drawing the figures. The work was supported by grants 16-3557.H-699 and 133/ 001-84154 from the Danish National Research Councils to D. von WeTtSTEIN.

\section{REFERENCES}

1. BENTON, W D \& R. W. DAVIS: Screening $\lambda$ gt recombinant clones by hybridization to single plaques in situ. Science 196, 180-182 (1977)

2. Broach, J. R. J N. Strathern \& J. B Hicks: Transformation in yeast: development of a hybrid cloning vector and isolation of the $C A N 1$ gene. Gene 8, 121-133 (1979)

3. Carle, G F. \& M V. Olson: An electrophoretic karyotype for yeast. Proc. Natl. Acad. Sci. USA 82, 3756-3760 (1985)

4. CONDE, J. \& G. R. FinK: A mutant of Saccharomyces cerevisiae defective for nuclear fusion. Proc. Natl. Acad. Sci. USA 73, 3651-3655 (1976)

5. DutCher, S. K.: Internuclear transfer of genetic information in karl-1/KARI heterokaryons in Saccharomyces cerevisiae. Mol. Cell. Biol. 1, 245 253 (1981)

6. Fincham, J. R.S. P. R DaY \& A. Radford: Fungal Genetics. Fourth edition. Blackwell Scientific Pub- lications. Oxford, London, Edinburgh and Melbourne (1979)

7. Guermansen, C \& P.SigsgaArd: Construction of a hybrid brewing strain of Saccharomyces carlsbergensis by mating of meiotic segregants. Carlsberg Res. Commun. 46, 1-11 (1981)

8. GRELL. R. F.: A new hypothesis on the nature and sequence of meiotic events in the female of Drosophila melanogaster. Proc. Natl. Acad. Sci. USA 48, 165-172 (1962)

9. Holmberg, S.: Genetic differences between Saccharomyces carlsbergensis and S. cerevisiae II. Restriction endonuclease analysis of genes in chromosome III. Carlsberg Res. Commun. 47, 233-244 (1982)

10. Holmberg, S., M. C. Kielland-Brandt, T. Nilsson-TIllgren \& J. G. L. Petersen: The ILVI gene in Saccharomyces cerevisiae: 5' and 3' end mapping of transcripts and their regulation. Carlsberg Res. Commun. 50, 163-178 (1985)

11. Holmberg. S. J. G. L. Petersen, T. Nilsson-TillGREN. C. GJermansen \& M. C. Kielland-BRANDT: Biosynthesis of isoleucine and valine in Saccharomyces. Gene structure and regulation. In: Biological Research on Industrial Yeasts, vol. 1, G. G. Stewart, I. Russel, R. D. Klein \& R. R. Hiebsch, eds. Uniscience Series, CRC press, Boca Raton (in press)

12. Ito, H., Y Fukada, K. Murata \& A. Kimura: Transformation of intact yeast cells treated with alkali cations. J. Bacteriol. 153, 163-168 (1983)

13. Kielland-Brandt, M C., C. Guermansen, T. Nilsson-Tillgren, J G. L. Petersen, S. HolmBERG \& P SIGSGAARD: Genetics of a lager production yeast. Tech. Q. MBAA 18, 185-187 (1981)

14. Kielland-Brandt, M. C., S. Holmberg, J G L. Petersen \& T Nilsson-Tillgren: Nucleotide sequence of the gene for threonine deaminase (ILVI) of Saccharomyces cerevisiae. Carisberg Res. Commun. 49, 567-575 (1984)

15. Loenen, W A. M. \& W J Brammar: A bacteriophage lambda vector for cloning large DNA fragments made with several restriction enzymes. Gene 10, 249-259 (1980)

16. Maniatis, T., E F Fritsch \& J. Sambrook: Molecular cloning. A laboratory manual. Cold Spring Harbor Laboratory, New York (1982)

17. McKnight, G L, T S. Cardillo \& F Sherman: An extensive deletion causing overproduction of yeast iso-2-cytochrome c. Cell 25, 409-419 (1981)

18. Mortimer, R K \& D SChiLD: Genetic map of Saccharomyces cerevisiae. Microbiol. Rev. 44, 519-571 (1980)

19. Murray, N E, W J Brammar \& K. Murray: Lambdoid phages that simplify the recovery of in 
vitro recombinants. Mol. Gen. Genet. 150, 53-61 (1977)

20. Nilsson-Tillgren. T., J G. L. Petersen, S. HolmBERG \& M. C. KIELLAND-BRANDT: Transfer of chromosome III during kar mediated cytoduction in yeast. Carlsberg Res. Commun 45, 113-117 (1980)

21. Nilsson-Tillgren, T., C. GJermansen, M.C. Kielland-Brandt, J. G. L Petersen \& S. Holmberg: Genetic differences between Saccharomyces carlsbergensis and $\mathrm{S}$. cerevisiae. Analysis of chromosome III by single chromosome transfer. Carisberg Res. Commun. 46, 65-76 (1981)

22. Nilsson-Tillgren, T., M.C. Kielland-Brandt, S HolmberG, J. G. L. Petersen \& C. GJermansen: Is lager yeast a species hybrid? Utilization of intrinsic genetic variation in breeding. In: Genetics of Industrial Microorganisms. Y. Ikeda \& T. Beppu, eds., pp. 143-147, Kodanska Ltd., Tokyo (1983)

23. Perkins, D D.: Biochemical mutants in the smut fungus Ustilago maydis. Genetics 34, 607-626 (1949)

24. Petersen, J. G. L., S. Holmberg, T. Nilsson-TillGREN \& M. C. Kielland-BRandT: Molecular cloning and characterization of the threonine deaminase ( $I L V I)$ gene of Saccharomyces cerevisiae. Carlsberg Res. Commun. 48, 149-159 (1983)

Accepted by E. LuND
25. Petersen, J G L., M. C. Kielland-Brandt, S Holmberg, T Nilsson-Tillgren \& C. GierMANSEN: Homeologous $I L V$ genes in Saccharomyces. In: Gene Expression in Yeast. M. Korhola \& E. Vaisainen, eds., Proc. of the Alko Yeast Symp., Helsinki 1983. Foundation for Biotechnical and Industrial Fermentation Research 1, 201207 (1983)

26. ROUYer, F., M. -C. Simmler, C. JohnsSon, G. Vergnaud, H. J. CoOKe \& J. Weissenbach: A gradient of sex linkage in the pseudoautosomal region of the human sex chromosomes. Nature 319, 291-295 (1986)

27. Shaffer, B., I. Brearley, R. LitTlewood \& G. R. FINK: A stable aneuploid of Saccharomyces cerevisiae. Genetics 67, 483-495 (1971)

28. SOUTHERN, E. M.: Detection of specific sequences among DNA fragments separated by gel electrophoresis. J. Mol. Biol. 98, 503-517 (1975)

29. WetTSTEIN, D. von, C. GJeRMANSEN, S Holmberg, M. C. Kielland-Brandt, T. Nilsson-Tillgren. M. B Pedersen, J. G. L. Petersen \& P Sigsgaard: Genetic engineering in the improvement of brewers yeast. Tech. Q. MBAA 21, 45-61 (1984) 